\title{
Towards the industrialisation of a transonic gust rig for simulation of gusts on half-models
}

DOI:

10.2514/6.2018-0626

\section{Document Version \\ Proof}

Link to publication record in Manchester Research Explorer

\section{Citation for published version (APA):}

Davidson, T. (2018). Towards the industrialisation of a transonic gust rig for simulation of gusts on half-models. Paper presented at 2018 AIAA Aerospace Sciences Meeting, Kissimmee, Florida, United States. https://doi.org/10.2514/6.2018-0626

\section{Citing this paper}

Please note that where the full-text provided on Manchester Research Explorer is the Author Accepted Manuscript or Proof version this may differ from the final Published version. If citing, it is advised that you check and use the publisher's definitive version.

\section{General rights}

Copyright and moral rights for the publications made accessible in the Research Explorer are retained by the authors and/or other copyright owners and it is a condition of accessing publications that users recognise and abide by the legal requirements associated with these rights.

\section{Takedown policy}

If you believe that this document breaches copyright please refer to the University of Manchester's Takedown Procedures [http://man.ac.uk/04Y6Bo] or contact uml.scholarlycommunications@manchester.ac.uk providing relevant details, so we can investigate your claim.

\section{OPEN ACCESS}




\title{
Towards the industrialisation of a transonic gust rig for simulation of gusts on half-models
}

\author{
Angel Gomariz-Sancha ${ }^{1}$, Andrew J. Peace ${ }^{2}$, David A. Roberts ${ }^{3}$ and Todd S. C. Davidson ${ }^{4}$ \\ Aircraft Research Association Ltd., Bedford, United Kingdom, MK41 7PF
}

\begin{abstract}
Recent developments of the gust simulation facility for the ARA Transonic Wind Tunnel along with verification and demonstration experiments are described. The facility was first reported in the open literature in 2015, when a test to prove the concept of gust production at transonic speeds through directed trailing-edge blowing from gust vanes positioned in the tunnel contraction was detailed. The electro-mechanical improvements to the gust vanes over the past two years are reviewed, including the enhancements to the blowing control system to allow gusts of uniform amplitude to be produced over a floor-mounted civil aircraft half-model. Experiments both to verify the improved control system and to demonstrate the impact of gusts on a half-model furnished with advanced optical diagnostics to measure the dynamic behaviour are discussed. It is concluded that the capability for transonic testing using the gust rig is maturing, but some improvements are still required before this unique facility can be considered fully industrialised.
\end{abstract}

\section{Nomenclature}

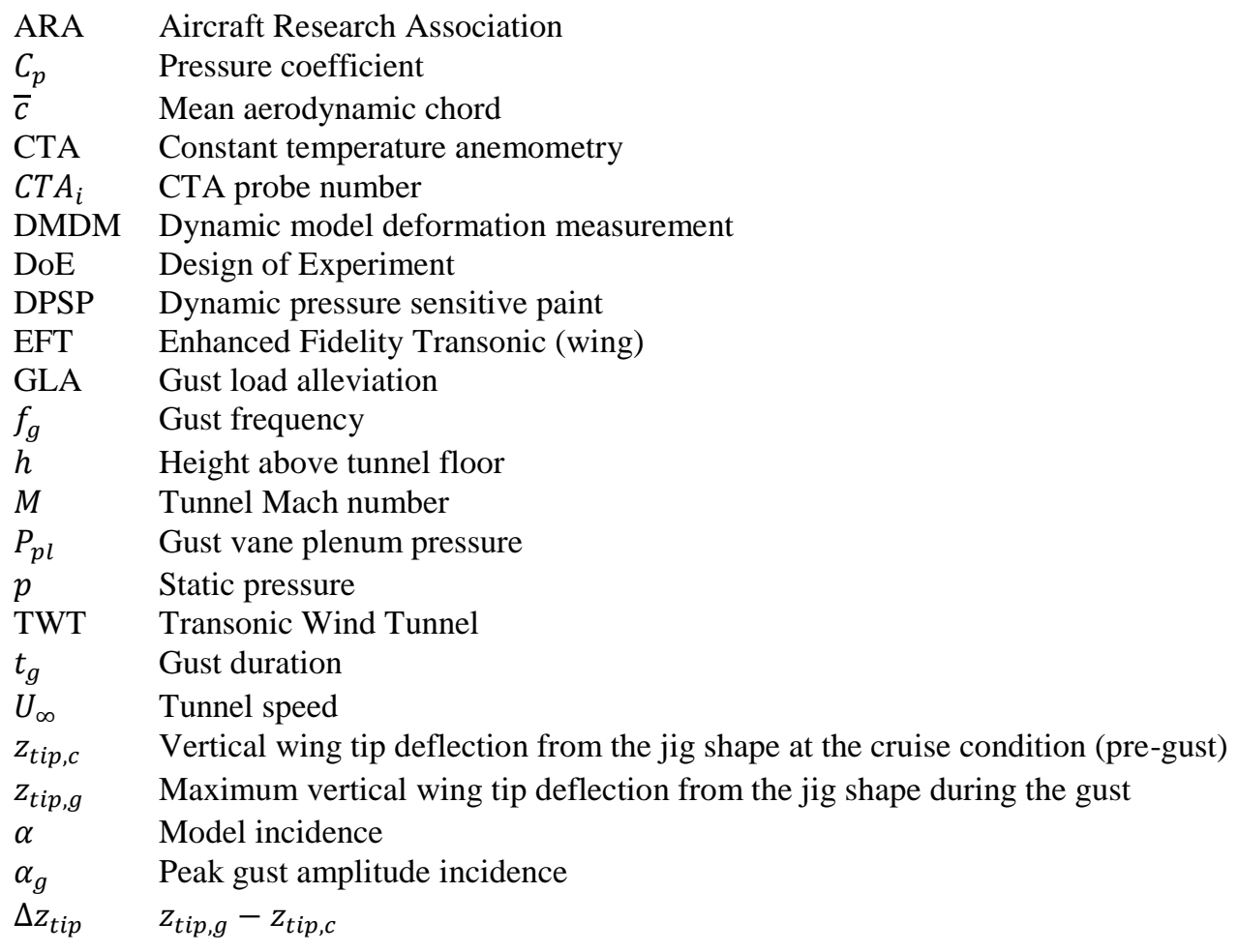

\footnotetext{
${ }^{1}$ Senior Aerodynamics Engineer, Aerodynamics Capability.

${ }^{2}$ Chief Scientist - Computational Aerodynamics. AIAA Senior Member.

${ }^{3}$ Technical Team Leader, Aerodynamics Capability.

${ }^{4}$ Optical Diagnostics Development Engineer. AIAA Member
} 


$\begin{array}{ll}\Delta \theta_{t i p} & \theta_{t i p, g}-\theta_{t i p, c} \\ \eta & \text { Spanwise position scaled by semi-span } \\ \theta_{t i p, c} & \text { Wing tip twist from the jig shape at the cruise condition (pre-gust) } \\ \theta_{t i p, g} & \text { Maximum wing tip twist from the jig shape during the gust }\end{array}$

\section{Introduction}

Aircraft manufacturers need to reduce the risk of late-stage re-design through improved early evaluation of new concepts, leading to a reduction in risk, overall costs and entry-into-service lead time. This implies a need for early assessment of critical loads, particularly where new load alleviation technologies are being introduced and historical data is of reduced value. As input to this, steady-state conditions for transonic aircraft can today be simulated successfully during design and verification studies using both numerical methods and ground testing. However, focus must also be placed on off-design conditions, where dynamic phenomena play an important role and unsteady loads are key. Here, the state of the art, both numerically and experimentally, is much further behind that for steadystate conditions. Currently, performance assessment of aircraft dynamic behaviour at the early design stages, including loading due to gusts, uses a mix of numerical simulation (simple models) and historical data. This process is not adequate for innovative aircraft configurations; the simple models are likely to be out of scope and the historical data will be unrepresentative. In addition, there is a dearth of good quality experimental data for code validation, as well as design and certification purposes, on the aerodynamic response to dynamic conditions, particularly gust response. The fact that gust response loads are a significant part of the overall critical load cases for an aircraft adds emphasis to the requirement for new capabilities. The lack of such capabilities drives designs to be overly conservative, particularly structurally, implying additional weight and, hence, environmental impact through excessive fuel burn and resulting emissions.

A wind-tunnel testing capability which allows accurate early gust response assessment of new designs, potentially with new aerodynamic concepts including gust load alleviation (GLA) devices, will lead to a very significant reduction in risk in the design process for the aircraft manufacturer. In addition, the availability of high quality wind-tunnel validation data will drive improvements in computational tools, leading to further cost/time reductions in the longer term. Several low-speed wind-tunnel facilities possess gust generation devices; see for example Ref. 1 and Ref. 2. The standard means of gust generation in such facilities is through oscillating or rotating parts, positioned upstream of the working section, which generate continuous sinusoidal disturbances downstream, of varying amplitude and frequency. However, such mechanisms are unsuitable for large scale transonic windtunnels, not least as the oscillating parts would themselves need to be large, creating unacceptable vibrations in the wind-tunnel structure at the higher speeds. An alternative solution is required.

The Aircraft Research Association (ARA) began a programme of work in 2012 to invent, design and manufacture a gust simulation solution for its $8 \mathrm{ft} \times 9 \mathrm{ft}$ transonic wind tunnel (TWT), under a UK government funded project entitled "Aircraft Loads Alleviation Technology". The minimum requirements were to be able to examine the response of half-models, mounted on the tunnel floor, to single, vertical (aircraft axis) gusts. In addition, it was desired to have the flexibility to vary the gust amplitude, gust duration and the gust profile in the working section, although it was realised that the so-called ' 1 -cosine profile' would be of most interest to future customers, due to its inclusion in aircraft certification requirements, Ref. 3. The chosen solution was based on controlled, directed trailing-edge blowing from two gust vanes positioned vertically in the contraction section of the TWT, this blowing creating a time-varying bulk swirl in the working section. The blowing was sourced by highpressure air feeding five separate reservoirs along the span of each gust vane, with each chamber possessing a large number of solenoid valves to allow fine control of the gust characteristics. The first version of the gust rig was tested in March 2014 and the concept was successfully proven, as documented in Ref. 4. It is believed that the concept used is unique in the world.

Although the results from the 2014 test showed that the gust generation concept was capable of meeting the minimum requirements, it was also clear that improvements were needed if the gust rig was going to operate and perform as intended. Firstly, electro-mechanical improvements were necessary; for example, some leakage of the high-pressure air used for the trailing-edge blowing inside the gust vanes was apparent. Secondly, although not directly measured in the 2014 test, it was accepted that for identical pressurisation of each of the five vane 
reservoirs, the gust in the working section would vary in amplitude across a floor-mounted half-model: a constant amplitude was desired. This implied the need to perform a characterisation of the gusts produced, for the range of input variables (tunnel Mach number, vane reservoir pressures, solenoid valve scheduling), and to use this data to determine a new control algorithm which would produce a gust of uniform amplitude in the appropriate part of the tunnel working section. Therefore, a further programme of work, also under UK government funding (ARCADE project), was recently undertaken in 2016-2017 to enhance the operation of the gust rig, to validate these improvements and to characterise the gusts produced using a flow-angle measurement rake. The culmination of this programme was an empty-tunnel test (save the rake) of the enhanced version of the gust rig in the TWT in March 2017.

The underlying working principles of the gust rig are described in section III, along with the electro-mechanical improvements that have been made to the gust vanes in the ARCADE programme. Section IV describes the developed methodology by which the new vane control algorithm is produced using gust characterisation data. The outputs from the March 2017 test and the use of the data in determining the new control algorithm are described in section $\mathrm{V}$.

Most recently, a further wind-tunnel test took place using the gust rig in July 2017, as part of a UK government funding collaborative project (EFT). This test had two purposes. The first was to demonstrate the use of the enhanced gust rig with a floor-mounted civil aircraft half-model in the TWT furnished with extensive diagnostic equipment - and equally importantly to obtain validation data for CFD simulations, particularly aeroelastic capabilities. As the main objective of the gust rig is to allow assessment of dynamic effects on aircraft due to gust response, this drives a need to be able to measure not only unsteady flow phenomena on the wind-tunnel model, but also the unsteady motion of the model. Current wind-tunnel models are fabricated to be very stiff, but all models deform to some degree and dynamic flow onset conditions, such as a gust, will cause dynamic deformation. The future of transient flow phenomena research lies in the creation of dynamically-scaled wind-tunnel models to mimic the dynamic effects observed for the real aircraft. ARA has recently introduced a dynamic model deformation measurement system (DMDM) for use in the TWT and this was used alongside the more established dynamic pressure sensitive paint system (DPSP) in this wind-tunnel test. The second purpose of the July 2017 test was to verify the new gust vane control algorithm, in terms of producing gusts of uniform amplitude in the region of the working section which would be occupied by a half-model. As in the ARCADE project, this was done using the flow-angle measurement rake in the otherwise empty tunnel.

Section VI describes the half-model test, giving details of the advanced optical measurement techniques (DPSP and DMDM) used and presenting results of representative examples from the very large dataset produced in this part of the experiment. The control algorithm verification experiment is discussed in section VII. In this section it is revealed that the output data from the experiment is indicating a residual deficiency in the performance of the gust rig; a potential cause is discussed. Conclusions are drawn in section VIII, which include an outline of the next planned phase of work in the gust rig development, leading to its industrialisation as a unique transonic facility.

\section{Gust rig working principle}

The gust generation mechanism of the ARA gust rig is based on the Coanda effect. It consists of tangential blowing of high-pressure air over the trailing edges of two rounded-base vanes to generate varying levels of flow turning as a function of the blowing jet momentum.

In order to control the release of high-pressure air to define the gust shape and duration, the ARA gust rig uses a total of 1,800 solenoid valves equally distributed in the two vanes. The control system of the gust rig allows the scheduling of 18 groups of 100 solenoid valves to be user defined.

The two vanes, of approximately $4 \mathrm{~m}$ height each, are located in the ARA TWT contraction, as shown in Fig. 1, upstream of the test section where a half-model would be installed. 
The trailing-edge blowing is only active in the lower $70 \%$ of the vanes, allowing the airflow in the top part of the wind-tunnel to move in the opposite direction to the gust being generated. This is necessary in order to avoid the gust being damped out in too short a distance downstream of the rig vanes due to the presence of the tunnel walls. This crossflow swirl produces a variable cross-plane velocity distribution, which translates into varying gust amplitude along the span of a typical half-model fixed to the floor of the TWT.

One of the enhancements to the rig introduced during the ARCADE project was the ability to independently control the pressure at which the air is stored in each of the 5 reservoirs installed along each vane. This capability provides the flexibility to vary the cross-plane velocity distribution generated in the tunnel by the blowing mechanism, in order to control the amplitude of the gust

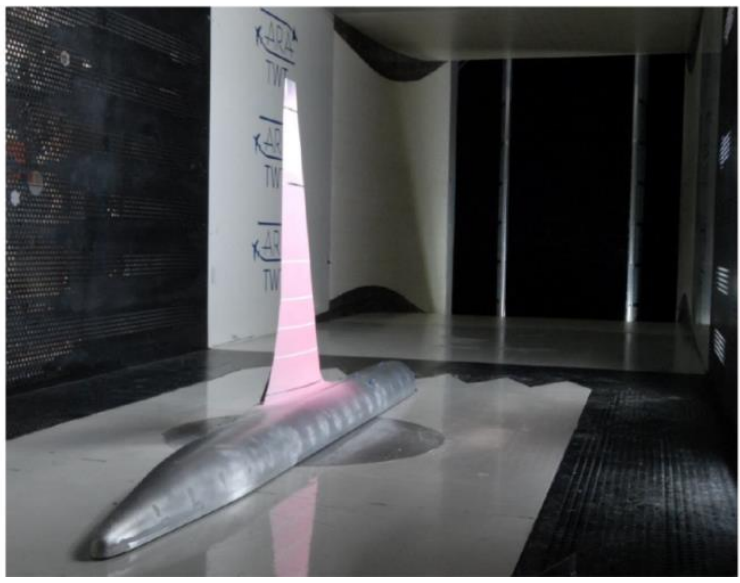

Fig. 1 ARA research model RBC12 sprayed with DPSP with gust rig vanes visible upstream, Ref. 4 produced across the model span.

Another electro-mechanical modification carried out during the ARCADE programme was focused on the rig's ability to generate both vertically positive (increased incidence) and negative gusts in the aircraft axis. This is achieved by diverting the high-pressure air released by the solenoid valves towards the port or starboard surface of the trailing edge of the vanes. The system used to direct the flow in the original configuration of the gust rig was a shuttle mechanism. It consisted of a sliding part, which was operated remotely, that switched between two positions, connecting the solenoid valves' manifold nozzle with the desired trailing-edge duct (Fig. 2, left). This mechanism was unsuccessful in the 2014 test; the motor used to drive the shuttle was unable to counteract the loads generated and hold the part in position. Given the unavailability of a motor that fulfilled the requirements of size and power to make the system successful, the design of a new diverter was developed: the paddle mechanism. It consists of a flap that is remotely driven to block one of the trailing-edge exit ducts and allow the flow to escape through the open passage (Fig. 2, right). The main benefit of this concept is that, unlike for the shuttle mechanism, the generated aerodynamic loads hold the flap in position.
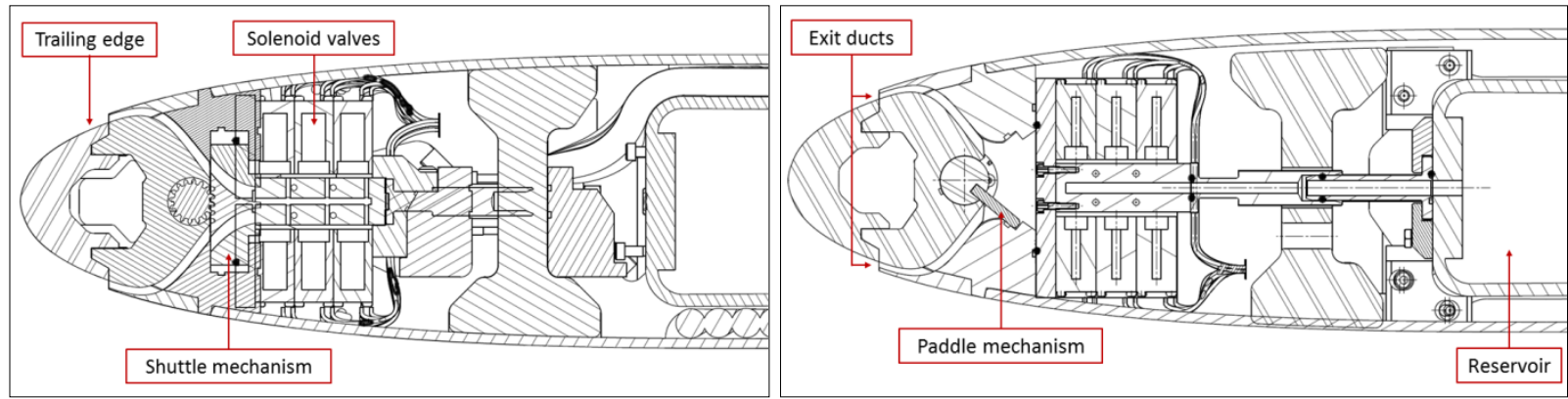

Fig. 2. Gust rig vane section with original shuttle mechanism (left) and modified paddle mechanism (right)

The re-design of internal seals and connections to eliminate air leaks, the work to increase the number of solenoid valves up to 900 per vane from the 780 installed in the March 2014 test and to make the second vane fully operational (only one vane was used during the 2014 test) complete the list of electro-mechanical upgrades performed during the period 2016-2017. 


\section{Gust vane control algorithm enhancement methodology}

In the process of the industrialisation of the ARA gust rig, emphasis has been placed on improving the uniformity of the gust peak amplitude across a half-model span. This is sought through creating an appropriate profile of gust vane plenum pressures.

A methodology to determine the necessary plenum pressure profiling has been developed. It commences with the creation of a surrogate model created from wind-tunnel data. The model consists of a multi-dimensional function which relates the peak gust amplitude $\alpha_{g}$ to all the independent variables, as in Eq. (1),

$$
\alpha_{g}=f\left(M, P_{p l_{i}}, t_{g}, h\right)
$$

where $M$ is the working section Mach number, $P_{p l_{i}}$ is the plenum pressure in the $\mathrm{i}^{\text {th }}$ reservoir, $t_{g}$ is the gust duration and $h$ is the tunnel height or, in aircraft axes, spanwise location of the measurement.

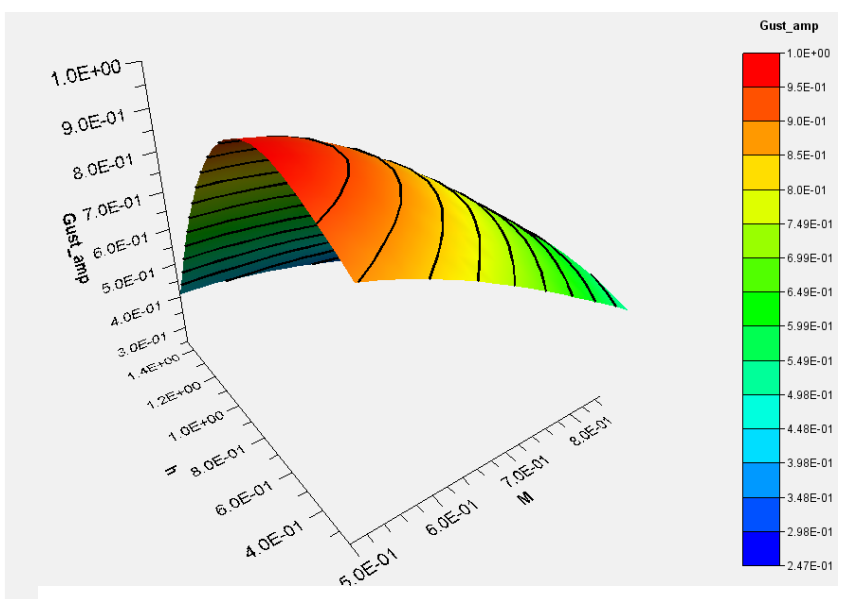

Fig. 3. Surface of the surrogate model generated from the ARCADE test database

The methodology uses a gradient-based optimisation algorithm (Direct Numerical technique NLPQLP - Sequential Quadratic Programming) to look efficiently for combinations of $P_{p l_{i}}$ values that fulfil two objectives: (i) minimise the gust amplitude standard deviation over the tunnel height and (ii) maximise the mean gust amplitude.

The values selected by the optimiser are combined with the conditions specified in the DoE stage $\left(M, t_{g}, h\right)$, which complete the set of independent variables in equation (1). The gust amplitudes are obtained from the response surface and the objectives are evaluated. The optimiser looks for a better combination of $P_{p l_{i}}$ until the optimum is found.
A representation of the gust amplitude versus the spanwise location and Mach number at fixed gust duration and plenum pressure distribution from the ARCADE surrogate model is shown in Fig. 3. Radial Basis Function approximation techniques were chosen for the curve fitting.

The surrogate model generated from the windtunnel data is then interrogated to extract the optimised reservoir pressures for the desired gust amplitude and wind-tunnel test conditions. The algorithm structure of the established methodology is shown in Fig. 4.

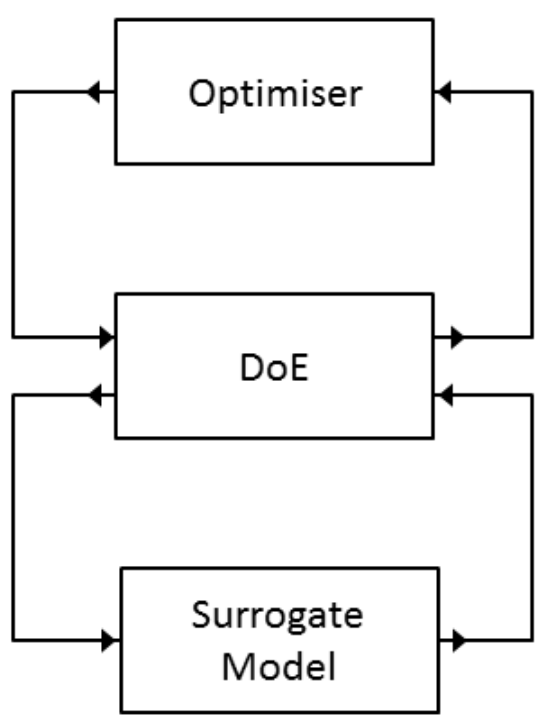

Fig. 4. Structure of the optimisation algorithm 


\section{Gust characterisation experiment}

The ARA gust rig performance was assessed during the March 2017 ARCADE project wind-tunnel test by verifying its ability to achieve the different gust characteristics that define an ideal gust. A selection of the results used to assess the repeatability, shape quality and amplitude of the gusts produced is presented here. It is important to note that, due to its relevance to the CS-25 airworthiness certification specifications, the 1-cosine gust shape was chosen for the assessment of gust shape quality performance; however, the ARA gust rig is able to produce different gust shapes, as shown in Fig. 5.
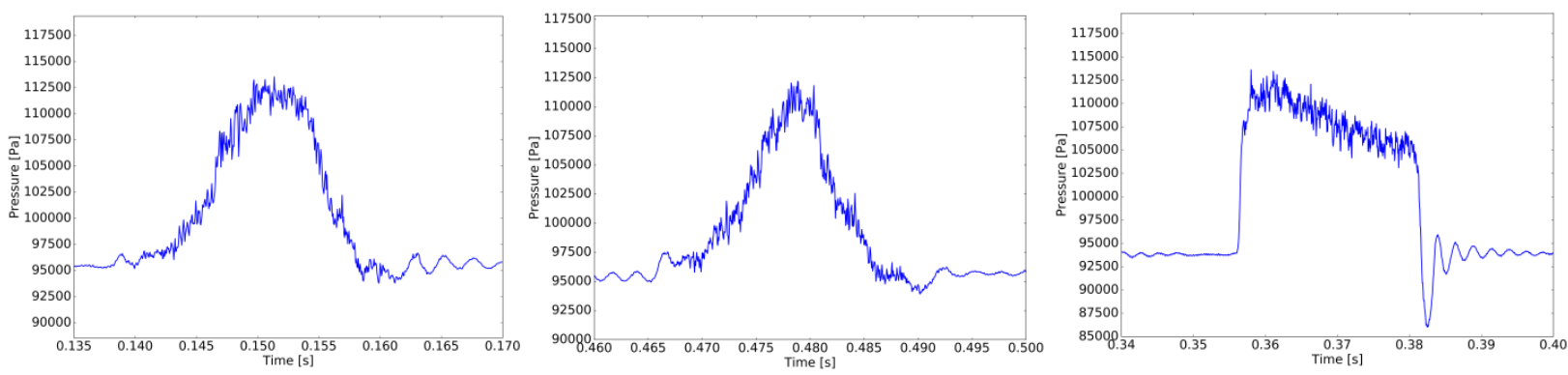

Fig. 5. Pressure signal measured at the rig flow-exit ducts: 1-cosine, triangle and square profiles requested

In order to characterise the gusts in the wind-tunnel test section, a flow survey was carried out by means of a rake which held five Constant Temperature Anemometry (CTA) dual-sensor cross-fibre probes. Since no half-model was installed in the tunnel test section during the flow survey, the rake was located at the tunnel centreline, allowing the probes to be positioned slightly ahead of where a half-model wing would be located.

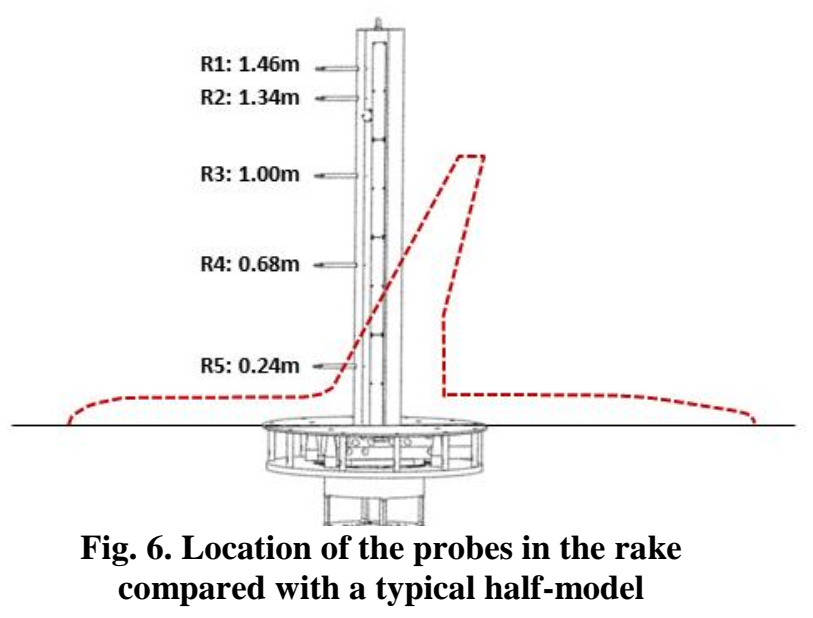

Fig. 6 shows the position of the 5 CTA probes R1 to R5 compared with a typical half-model in the ARA TWT. It can be observed that the distribution of CTA probes allows the flow survey of an area that comfortably covers the area of interest.

The test programme consisted of the generation of more than 1,500 gusts with varying tunnel and rig conditions, produced in blocks of six repeated gusts. This allows the analysis of the rig repeatability performance and, at the same time, the definition of the generated gust as the average of the six gusts produced. The number of repetitions was chosen following Ref. 5, which also recommended a $200 \mathrm{~Hz}$ phase-free-low-pass filter be used for CTA measurements in order to capture the features of the gust response, without too much contamination from the background turbulence.

In the ARCADE test, the gusts were produced at a range of Mach numbers $(0.5,0.7$ and 0.85$)$, pressure distributions for the vane reservoirs (pressures between 2 and 9Bar gauge), gust durations (8, 10, 20, 50 and 100 $\mathrm{ms}$ ), desired gust shapes (1-cosine, triangle and square) and directions (positive and negative in a half-model coordinate system). Fig. 7 shows the arrangement of the elements of the flow survey. 


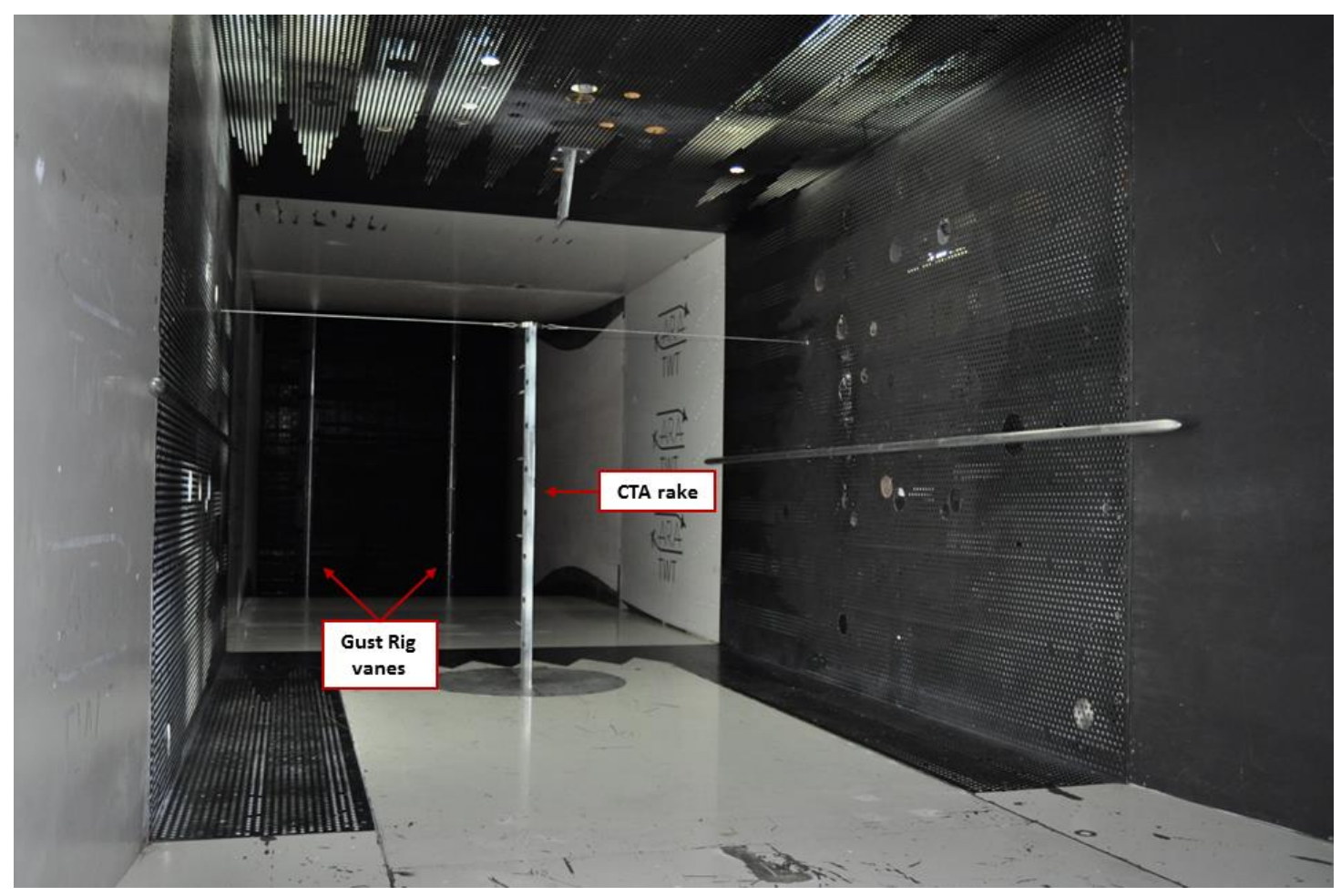

Fig. 7. Arrangement of the main elements of the gust rig test in the ARA TWT - March 2017

In order to assess the gust rig repeatability performance, Fig. 8 shows an example of the standard deviation (black line) of the six produced gusts that form the averaged gust (blue line) measured by the CTA probe R2 at two different Mach numbers.

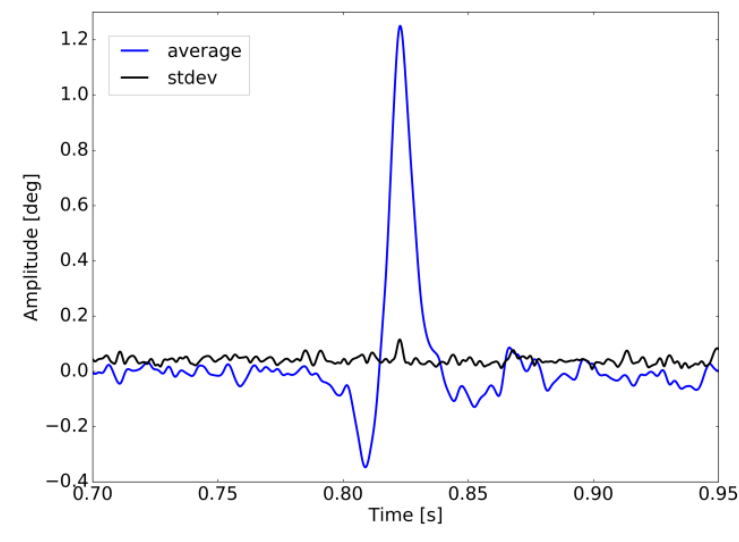

(a) $\mathrm{M}=\mathbf{0 . 5}$

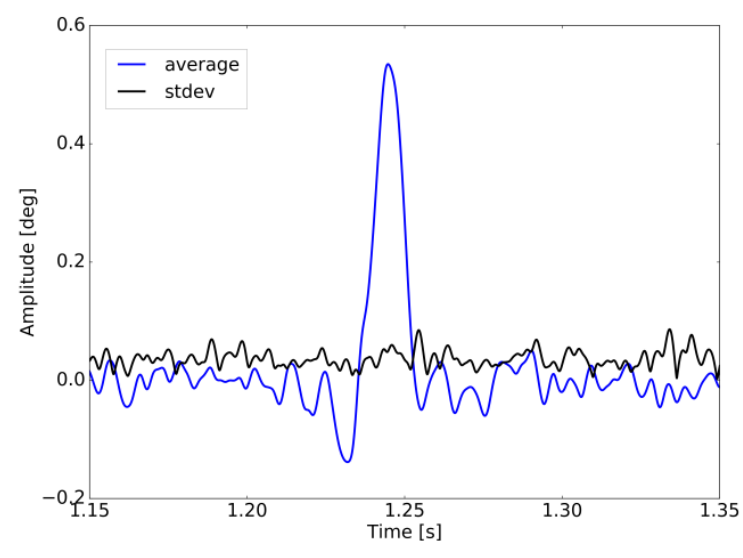

(b) $\mathrm{M}=\mathbf{0 . 8 5}$

Fig. 8. Repeatability performance - Probe R2 measurements in ARCADE test

The examples selected in Fig. 8 are representative of the gust rig performance repeatability, which show a standard deviation below $0.1^{\circ}$.

In order to assess and compare the shape of the 1-cosine gusts produced at different rig settings i.e. reservoir pressures and gust duration, the gust amplitudes and durations were non-dimensionalised. A sample of the studied cases is presented in Fig. 9, which shows how the shapes of gusts generated at different conditions collapse and how they compare with the ideal 1-cosine profile. The presented gust measurements were taken at the position where the 
mid-span station of a typical half-model would be (probe R4), and show that the gust shape measured in the windtunnel test section is very close to the 1 -cosine shape defined in the solenoid valve scheduling.

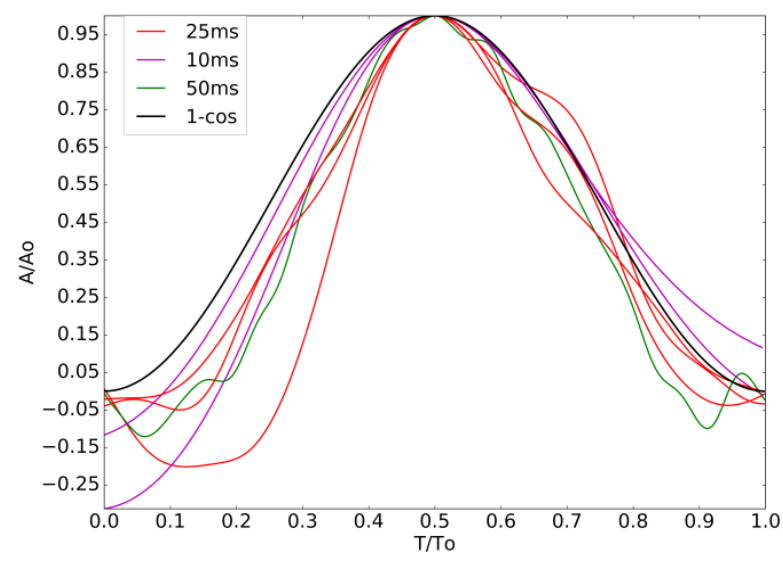

Fig. 9. Non-dimensionalised gusts at constant pressure measured by probe $\mathrm{R} 4-\mathrm{M}=\mathbf{0 . 8 5}$

An example of the gust amplitude measured by each of the rake CTA probes is presented in Fig. 10. It shows how the maximum gust amplitude varies for $\mathrm{M}=0.85$ at different tunnel heights, when a 1 -cosine gust of $25 \mathrm{~ms}$ of duration is requested and all the reservoirs are kept at 9Bar gauge (10Bar absolute). Note that probe R5, at the bottom of the rake, failed at this Mach number. Clearly, the gust amplitude has significant variation with height for these input settings.

The spanwise distribution of the gust peak amplitude is shown in Fig. 11. In this figure a gust of $25 \mathrm{~ms}$ was produced at $\mathrm{M}=0.5$ with all the reservoirs storing air at the maximum pressure (9Bar gauge). At this Mach number, no probes failed.

Fig. 11 clearly shows the effect of the swirl generated by the blowing mechanism on the spanwise gust amplitude distribution. It is worth noting that Fig. 11 does not cover the whole tunnel height and that near the tunnel ceiling, the gust evolves in the opposite direction. The comparison of the maximum gust amplitudes achieved in Fig. 10 and Fig. 11 with the same reservoir pressures shows that the maximum gust amplitude decreases as the Mach number increases.

The ARCADE test was not only designed to assess the current gust rig performance, but also to gather the data needed to identify enhanced rig settings to further improve its performance, thus the high number of data points produced. The data collected in the test allowed the generation of a surrogate model which, linked to the optimisation methodology described in section IV, would provide new optimised settings of the gust rig control system. The relationship of three variables - gust
As expected, in all cases a starting vortex is generated, which delays the start of the gust profile and causes a deviation from the ideal shape. This effect cannot be removed, since it is a physical consequence of changing the circulation around the vanes. The analysis of the gust shape performance also revealed that gusts with periods $t_{g} \geq 50 \mathrm{~ms}$ show oscillations in their profile. The cause of this phenomenon is yet to be determined.

Measurements by probe R1, not shown here, revealed that it is very difficult to control the gust shape at tunnel heights close to the centre of the swirl generated by the blowing mechanism. Nevertheless, this position is far from the area of interest, which is where a typical halfmodel would sit, as shown in Fig. 6.

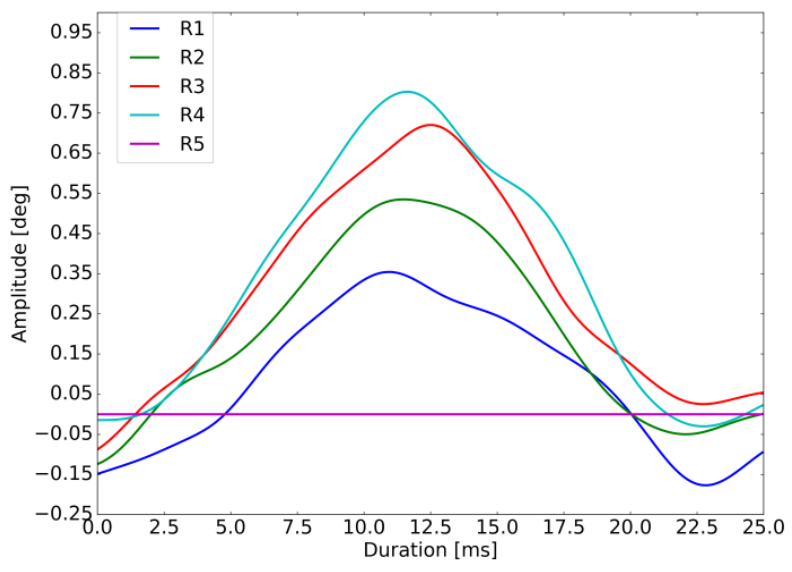

Fig. 10. Gust amplitude spanwise variation $\mathrm{M}=0.85, \mathrm{t}_{\mathrm{g}}=25 \mathrm{~ms}, \mathrm{P}_{\mathrm{pl}}=9 \mathrm{Bar}$

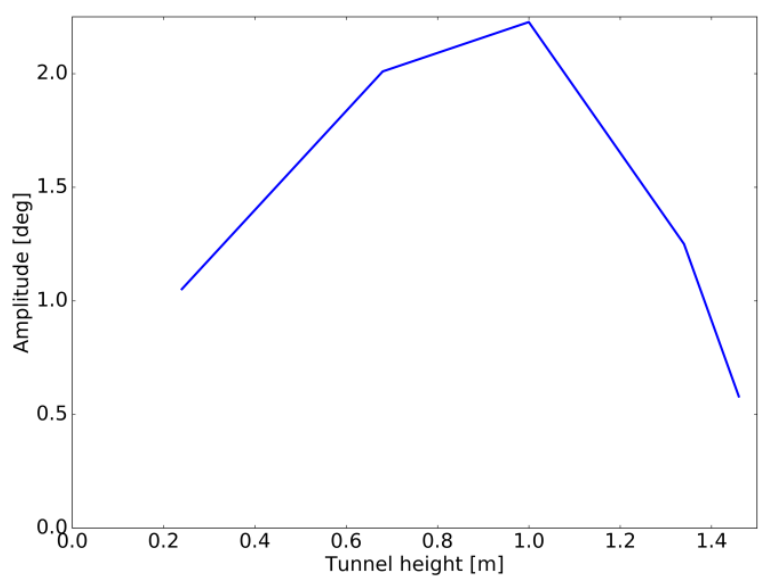

Fig. 11. Maximum gust amplitude spanwise distribution across the rake span $-M=0.5$, $t_{\mathrm{g}}=25 \mathrm{~ms}, \mathrm{P}_{\mathrm{pl}}=9 \mathrm{Bar}$ 


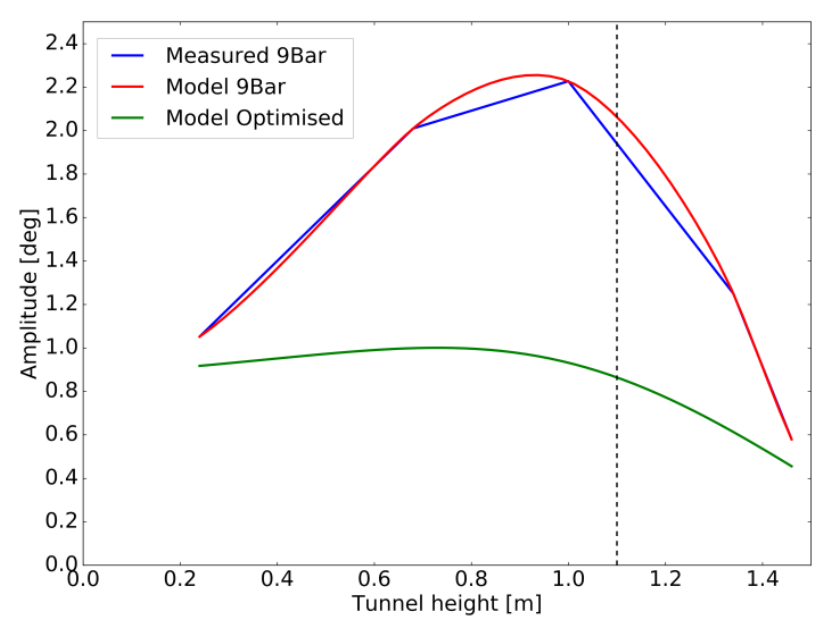

Fig. 12. Spanwise gust amplitude distributions. $M=0.5, t_{\mathrm{g}}=25 \mathrm{~ms}$ amplitude, tunnel height and Mach number - provided by the multi-variable surrogate model created from the windtunnel test data is shown in Fig. 3.

The optimisation results of the case presented above $\left(M=0.5, t_{g}=25 m s\right)$ using the ARCADE wind-tunnel data to generate the surrogate model are shown here as an example. Although gust amplitude measurements were taken in a broader range, only the gust amplitudes in spanwise locations $h \leq 1.1 \mathrm{~m}$ were targeted in this optimisation. This range was selected because $1.1 \mathrm{~m}$ is the half-span length of the civil aircraft model shown in Fig. 1 and tested as part of the EFT project, as described in section VI. However, the results of other optimisation strategies were also tested during the EFT test campaign. These strategies consisted of variations to the spanwise optimisation range as well as to the constraints on the allowed reservoir pressure range.

The optimised reservoir pressures for the example case using the baseline optimisation strategy $(h \leq 1.1 \mathrm{~m}$ and maximum $P_{p l_{i}}=9 \mathrm{Bar}$ gauge) are, from top to bottom reservoirs: $P_{p l_{1}}=2.0 \mathrm{Bar}, P_{p l_{2}}=8.0 \mathrm{Bar}, P_{p l_{3}}=5.6 \mathrm{Bar}$, $P_{p l_{4}}=8.0 \mathrm{Bar}, P_{p l_{5}}=4.8 \mathrm{Bar}$, which are predicted to produce a gust whose mean amplitude and amplitude standard deviation along the model span are $0.94^{\circ}$ and $0.05^{\circ}$, respectively.

Fig. 12 shows the optimised spanwise gust amplitude distribution at the wind-tunnel test section predicted by the surrogate model, alongside the experimentally measured distribution for the uniform plenum pressures $\left(P_{p l_{i}}=9 \mathrm{Bar}\right.$ gauge) and the corresponding surrogate model prediction.

It can be observed in Fig. 12 that the gust angle expected with the optimised reservoir pressure distributions is significantly lower than the maximum obtained when the maximum pressure in the reservoirs is applied (9Bar gauge). It is important to note that the maximum uniform gust amplitude possible is driven by the minimum local amplitude achievable with the maximum reservoir pressure which is normally found at the lower tunnel heights.

\section{Civil aircraft half-model experiment}

An experiment was conducted as part of the EFT project using ARA's reference civil aircraft half-model, designated $\mathrm{RBC} 12$, which has been used in several recent research projects, for example, an investigation into highspeed buffet, see Ref. 6. The model is a wing-body configuration and the general layout is shown in Fig. 13. Transition bands were used on the model, set at $15 \%$ chord on the upper surface and $5 \%$ on the lower surface. It was mounted on a 5-component balance on ARA's half-cart turntable; however, balance data was not a key output of the experiment. The wing is furnished with 274 static pressure tappings and 23 unsteady pressure transducers, the latter positioned on the outer wing upper surface. The unsteady transducers were introduced as part of the previous buffet experiment, as were 8 accelerometers to measure structural vibrations and a wing-root strain gauge.

Two recently developed advanced optical measurement techniques - Dynamic Pressure-Sensitive Paint (DPSP) and Dynamic Model Deformation Measurement (DMDM) - were used during the test campaign. These techniques give full surface coverage, in comparison with traditional discrete measurements such as high frequency pressure transducers, which were used as a measure of verification of the DPSP output, and accelerometers, providing invaluable data to assist in the evaluation and understanding of the aerodynamic and structural response of the model to the gust. Complete surface measurement also provides a significant increase in the data available for validation of numerical simulations. The DPSP and DMDM techniques, which were used separately in the test, and the results they provided are discussed next. 


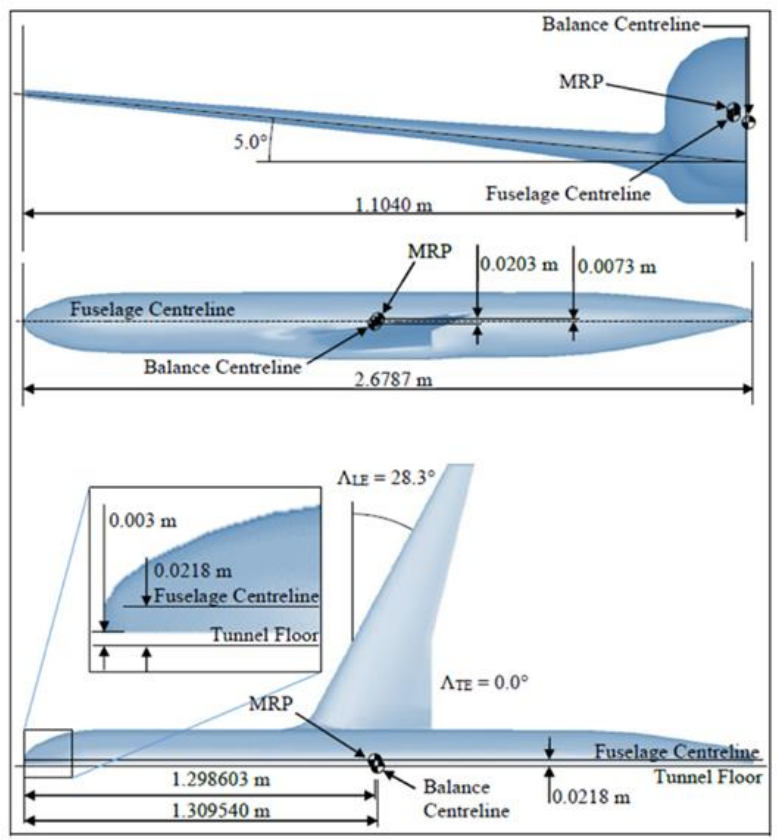

Fig. 13. General layout of the RBC12 half-model.

\section{A. Dynamic Pressure-Sensitive Paint}

Dynamic Pressure-Sensitive Paint (DPSP) is used to measure the time-resolved static pressure on the model surface. Numerous prior publications, such as Ref. 7, explain in detail the workings of these paints and so only a brief overview is presented here. The model is illuminated with ultra-violet light, which is absorbed by luminophores in the paint. These then re-emit photons in the red spectrum, with the emission being quenched by the presence of oxygen molecules. The imaged intensity is then proportional to the local pressure at the model surface. A porous structure to the paint allows rapid diffusion of air molecules and so pressure fluctuations beyond $10 \mathrm{kHz}$ can be resolved.

The model was coated with ISSI Porous FastResponse Pressure-Sensitive Paint [Ref. 8] and illumination provided by ISSI LM-2XX-DM 2-inch $12 \mathrm{~W}$ continuous water-cooled LED lamps - three on the lower surface of the wing, four on the upper. Images of the wing upper and lower surfaces were recorded at 2,000 frames per second using Vision Research Phantom V1610 \& V1611 high-speed cameras, which provided

12-bit images at a resolution of $1024 \times 768$ pixels and apertures from 2.0 to 4.8 depending on flow condition, with 1,375 frames captured per acquisition - almost $0.7 \mathrm{~s}$ of data. The sample rate was chosen to be above the Nyquist criterion for the expected model response frequencies and to give sufficient image exposure times. The cameras were equipped with $35 \mathrm{~mm}$ lenses and 'red' optical filters to cut out the incident UV light.

The time-average intensity of the DPSP was calibrated against static pressure taps spanning the wing surface. This was conducted in Matlab using ARA's proprietary DPSP processing code. DPSP is a purely ratiometric technique, where wind-on images are referenced to an image of known condition (i.e. quiescent/wind-off). To reduce noise within the image, a $3 \times 3$ pixel Gaussian filter was applied to each frame of data captured, including the wind-off reference. Some small re-alignment was required due to camera movement between frames, caused by the cameras being mounted on the vibrating wind tunnel structure. Once processed, time-histories of the surface static pressure were available and the effect of the gust on the aerodynamic characteristics of the wing could be investigated (sub-section C).

\section{B. Dynamic Model Deformation Measurement}

Dynamic Model Deformation Measurement (DMDM) is able to track the three-dimensional deflection of a surface through time, using a two-camera stereoscopic system and a technique known as Digital Image Correlation [Ref. 9], an overview of which is given here. A pair of high-speed cameras is used to image the surface of interest, which is covered in a high-contrast stochastic pattern, such that each small region is uniquely identifiable in each frame of both camera views. The stereoscopically visible region is transformed from pixel space into 3D space by imaging a calibration plate covered in a Cartesian grid of markers with known spacings. Using the plate geometry and the camera sensor formats, the orientation of the Cartesian grid within each image is used to calculate the position of each camera within 3D space, as well as the lens parameters. This provides a 3D mapping of the stereoscopically visible region, and so the shape of the surface of interest can be calculated through time.

For the DMDM experiment, the Phantom cameras were installed to view the wing upper surface. As the model was already painted with DPSP (a light pink non-reflective coating), the high contrast pattern was achieved with black marker pen and illuminated using the UV lamps already in place. The same lenses, frame rates, resolutions and acquisition periods were used as with the DPSP, but instead employing 'yellow' optical filters and an aperture of 6.7 . 
LaVision's Davis StrainMaster software was used to calibrate the camera system and to convert the images into surface and deflection data. ARA proprietary Matlab codes were used to import the images in to StrainMaster and subsequently to post-process the resulting data. This involved using the point-to-plane Iterative Closest Point method [Ref. 10] to register the point cloud produced by StrainMaster to a CAD generated geometric model and then interpolating the deformations onto a spanwise/chordwise grid for each frame through time for each acquired gust measurement. The bending of the wing is then easily extracted as mean vertical displacement of each chord line along the span, while wing twist is calculated from the chordwise gradients of vertical displacement for each spanwise station. Once processed, time-histories of the model deformation could be investigated to aid in the characterisation of the model response.

\section{Experiment results}

For DPSP, 72 unique gusts were fired over the RBC12 model, covering the range:

- $\quad$ Mach number, model incidence - $(0.5,0.0),(0.5,2.0),(0.7,0.0),(0.7,2.0),(0.82,0.0),(0.82,1.0)$

- Gust vane reservoir pressures - as determined from the work described in section IV, including alternative optimisation strategies

- Gust direction - starboard only (tunnel axes), positive gust (model axes)

- Gust duration - $10 \mathrm{~ms}, 25 \mathrm{~ms}, 50 \mathrm{~ms}$

- Gust valve scheduling profile - mainly 1-cosine, with a small number of variations

The combination of model incidence and predicted gust peak amplitude at the highest Mach number tested was chosen so as to keep the effective onset incidence below that of buffet onset, as determined from Ref. 6. For each gust case, six nominally identical gusts were fired in succession, so that the repeatability of the gust could be assessed and (some) random effects could be averaged out during data post-processing. The variations from 1-cosine in the gust valve scheduling profile were a sensitivity test to discover how small variations in a 1-cosine valve profile would affect the gust shape over the model. For DMDM, 24 gusts were fired covering the same parameter range as above for DPSP, except that gust vane plenum pressures from only the baseline optimisation strategy, described in section $\mathrm{V}$, were chosen. There were no repetitions, so no averaging was possible.

Data were successfully obtained from all diagnostic techniques for all gusts fired in the test. Two gust cases are chosen here to demonstrate the outputs and to highlight some key features from the test; the details are given in Table 1. These cases are at the upper range of Mach number used in the test, selected as the change in the shock position on the wing upper surface during the gust event gives the best visual impression of the gust impact. In addition to giving the gust duration, this table also defines the gust event in terms of a frequency, which will prove useful in what follows.

\begin{tabular}{|c|c|c|c|c|c|c|c|}
\hline Gust Case ID & $\mathbf{M}$ & $\left.\boldsymbol{\alpha} \mathbf{(}^{\circ}\right)$ & Gust profile & $\boldsymbol{t}_{\boldsymbol{g}}(\mathbf{m s})$ & $\boldsymbol{\alpha}_{\boldsymbol{g}}\left(^{\circ}\right)$ & $\boldsymbol{U}_{\infty}\left(\mathbf{m s}^{-1}\right)$ & $\boldsymbol{f}_{\boldsymbol{g}}(\mathbf{H z})$ \\
\hline $\mathrm{GC} 1$ & 0.82 & 1 & $1-\cos$ & 50 & 0.67 & 269 & 20 \\
\hline $\mathrm{GC} 2$ & 0.82 & 1 & $1-\cos$ & 25 & 0.73 & 269 & 40 \\
\hline
\end{tabular}

Table 1 Gust case details

Clearly, only an impression of the unsteady flow over the wing and unsteady motion of the wing during the gust impact can be given using static images in this paper. Nevertheless, it is believed the following images demonstrate the quality and usefulness of the data taken in this gust rig test.

Fig. 14 and Fig. 15 show snapshots of surface pressure from the processed DPSP data for GC1 and GC2, respectively. The top and middle images depict $C_{p}$ prior to the gust impact and at the gust peak, respectively, along with the time history for mean $C_{p}$ over the upper surface. The bottom image depicts percentage deviation from the mean pressure for each pixel in the image, along with the time history of percentage pixel-pressure deviation averaged over the upper surface. The red dot indicates the snapshot positioning on the trace and the gust peak is defined as the maximum pressure variation. The impact of the gust on the shock position can clearly be seen for both 
cases, through the increment in effective onset incidence due to the gust moving the shock wave more rearward on the wing surface, as would be expected in this attached flow regime. The bottom image in each figure provides the clearest view of changes to the lambda shock structure at the gust peak.

Fig. 16 and Fig. 17 show snapshots of wing bending from the processed DMDM data for GC1 and GC2, respectively, with the top image taken prior to the gust impact and the bottom image taken at the gust peak. Here, the gust peak is defined as the peak in wing bending at the tip, as depicted in the traces below the images; the red dot indicates the snapshot positioning on the trace. The bending deflection is measured from the model's jig shape, so the bending prior to the gust event is the steady cruise bending. The impact of the gust on bending near the tip (being the maximum for the wing) can clearly be seen for both cases. However, it is clear from the tip bending traces that the post-gust behaviour is very different for the two cases. The gust appears to cause no further bending oscillations after the gust event for GC1, but significant post-gust oscillations are present for GC2. The two cases differ in gust duration, $50 \mathrm{~ms}$ for $\mathrm{GC} 1$ and $25 \mathrm{~ms}$ for $\mathrm{GC} 2$, which correspond to events with a frequency of $20 \mathrm{~Hz}$ and $40 \mathrm{~Hz}$, respectively, as given in Table 1. Ref. 6 states that the first wing bending mode for the RBC12 model is approximately $40 \mathrm{~Hz}$, which indicates that the $25 \mathrm{~ms}$ gust is exciting this natural mode of the wing and causing significant oscillations. This is gratifying, as it provides confirmation that the gust duration is as expected.

The bending excitation for GC2 is not visible in the mean $\mathrm{C}_{\mathrm{p}}$ gust trace in Fig. 15. As pure wing bending does not have a strong effect on wing aerodynamics, this is expected. A much more significant effect on wing aerodynamics is wing twist. However, the RBC12 model is very stiff in twist; the DMDM data shows that the peak incremental twist at the tip during the gust event for $\mathrm{GC} 1$ and $\mathrm{GC} 2$ is $0.07^{\circ}$ and $0.12^{\circ}$, respectively. Moreover, the first torsional mode of the wing is approximately $330 \mathrm{~Hz}$, so this would not be excited by the gust events. 


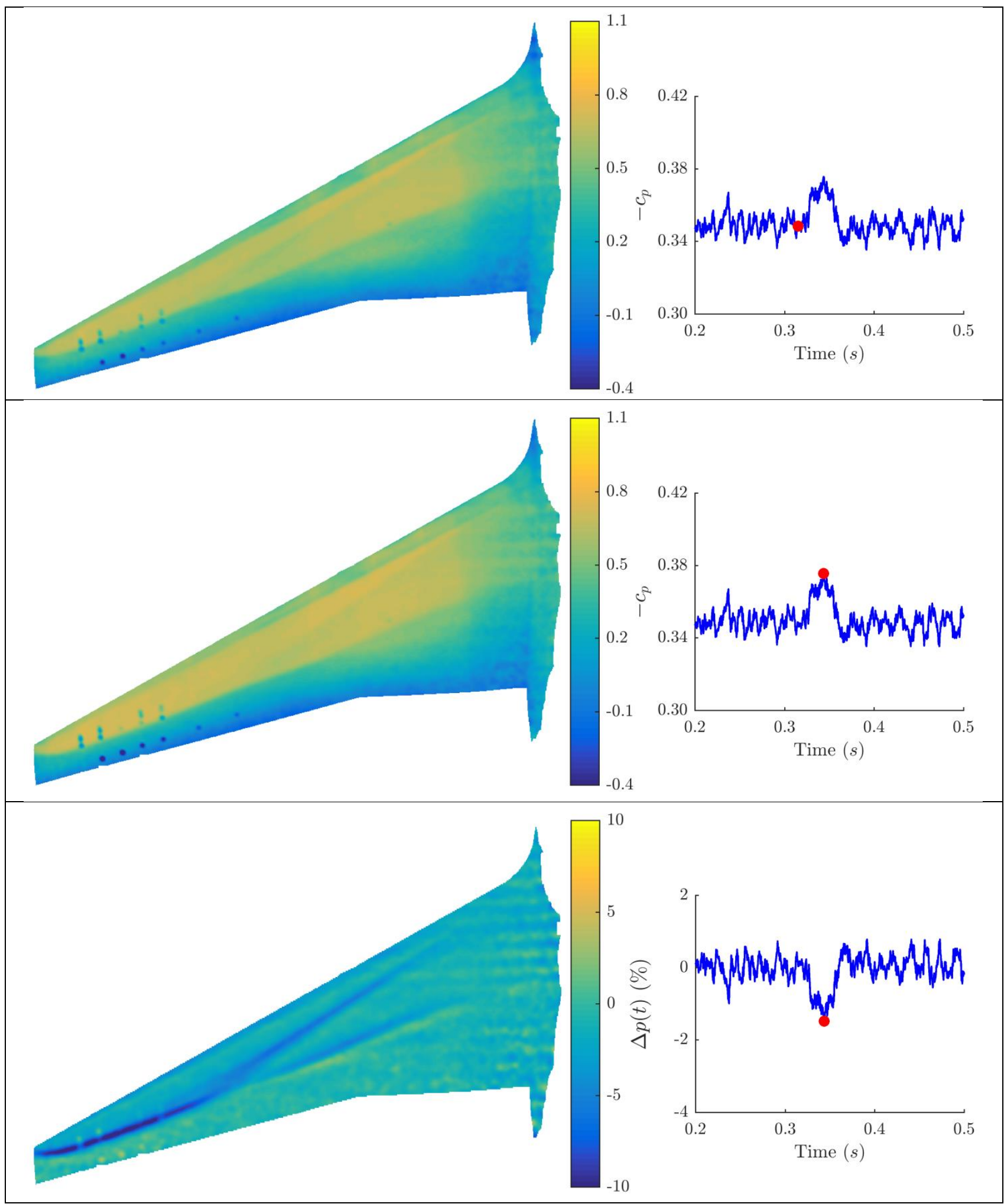

Fig. 14 Snapshot images of upper surface pressure and mean pressure variation time history for Gust Case 1 - top, pre-gust $\mathrm{C}_{\mathrm{p}}$; middle, gust peak $\mathrm{Cp}$; bottom, gust peak pixel percentage pressure variation from mean. 


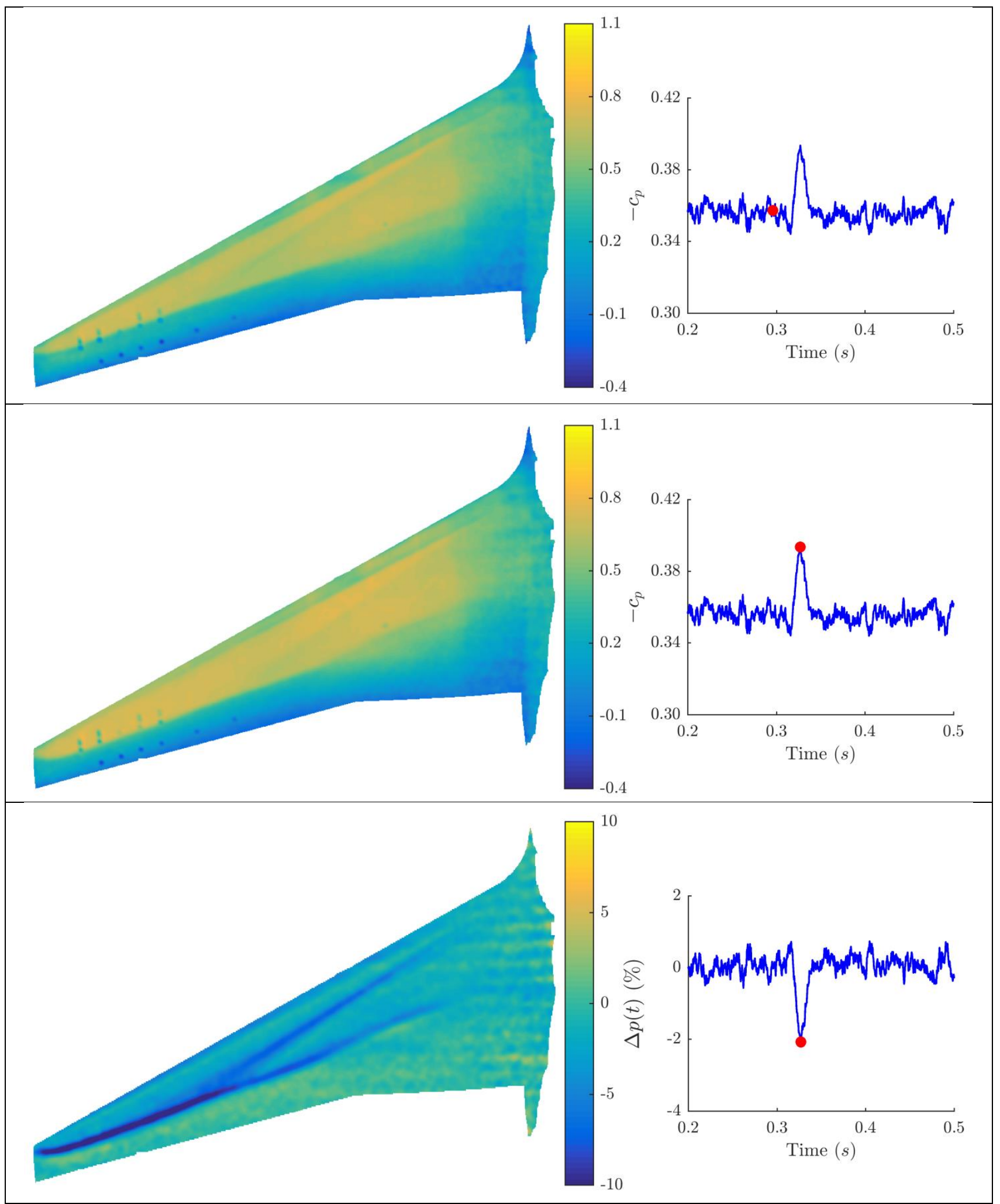

Fig. 15 Snapshot images of upper surface pressure and mean pressure variation time history for Gust Case 2 - top, pre-gust $C_{p}$; middle, gust peak $C_{p}$; bottom, gust peak pixel percentage pressure variation from mean. 


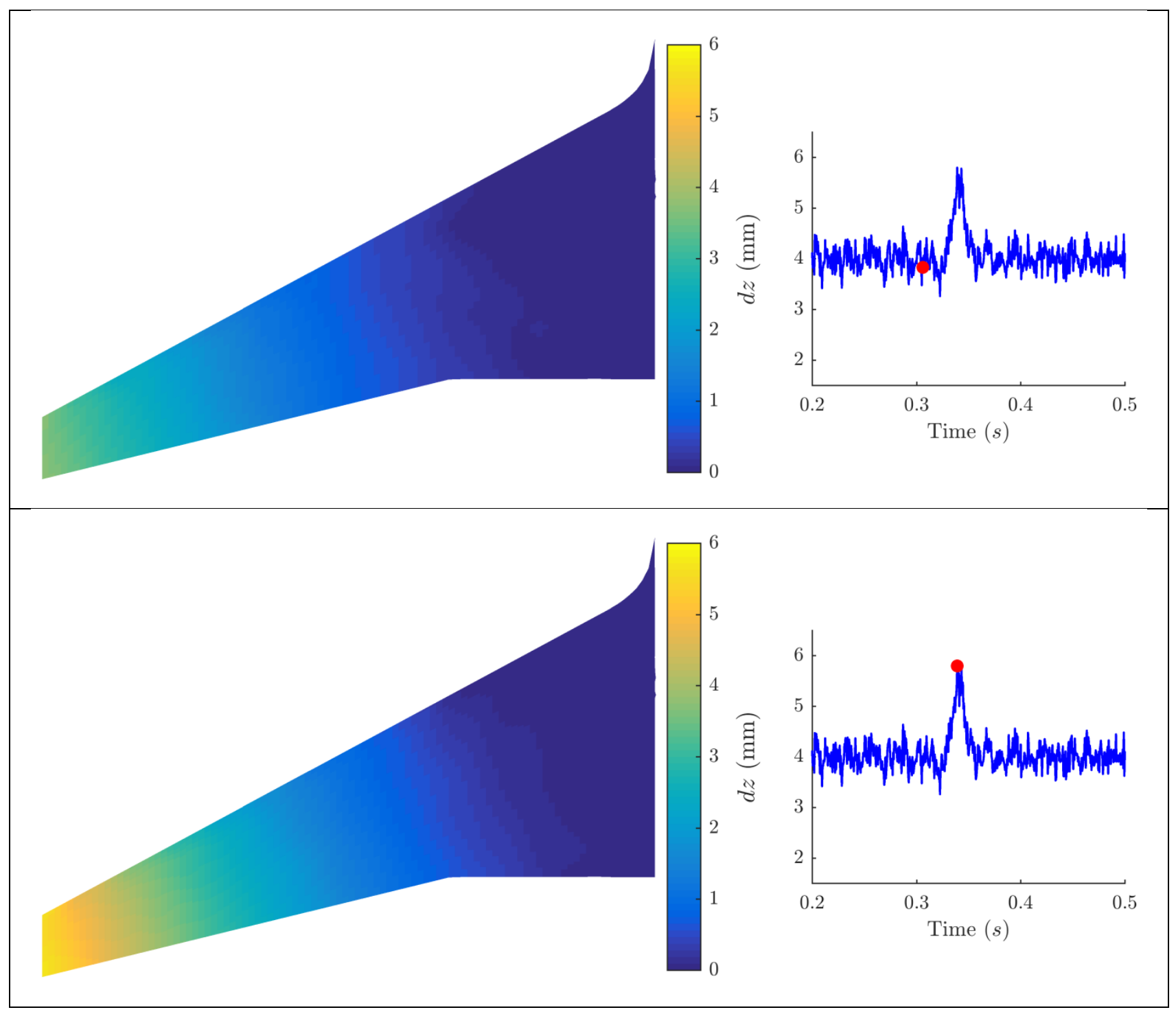

Fig. 16 Snapshot images of wing bending and wing tip bending time history for Gust Case 1 - top, pregust; bottom, gust peak 


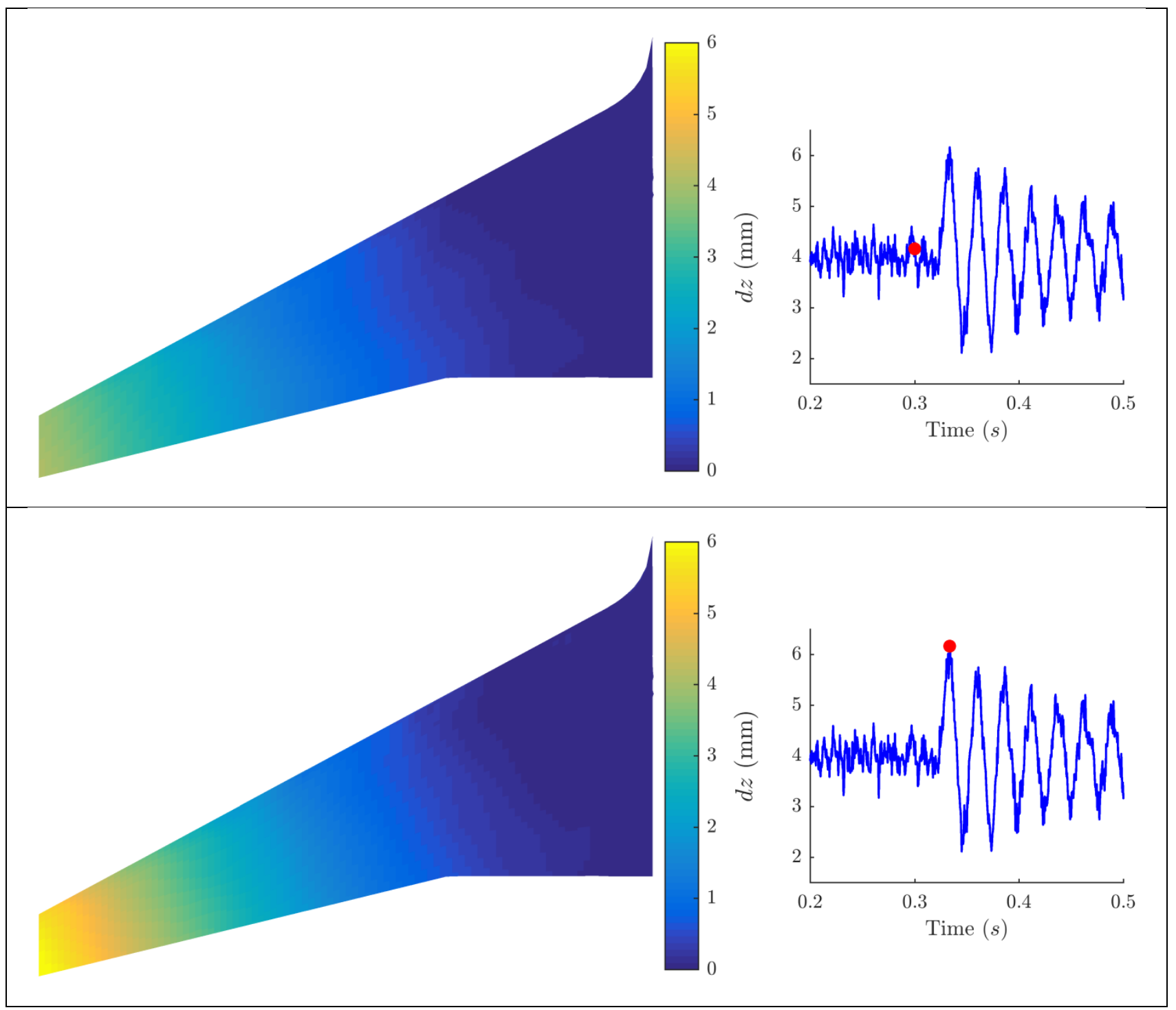

Fig. 17 Snapshot images of wing bending and wing tip bending time history for Gust Case 2 - top, pregust; bottom, gust peak

The wing tip bend and twist for both cases are given in Table 2. The error in bend arising from the DMDM measurement process is estimated to be $0.1 \mathrm{~mm}$ and $0.1^{\circ}$ for the twist at the tip. The cruise bend and twist for identical $(M, \alpha)$ combinations should be the same and the data in Table 2 is consistent with this. It is interesting that both the peak tip bend and twist is greater for the shorter gust (GC2). As the projected peak gust amplitude is approximately the same for both gusts, see Table 1, with GC2 being just less than $10 \%$ higher than GC1, this suggests that a higher degree of unsteadiness exists for the shorter gust, as would be expected. However, caution is needed here, as the twist values are of the same order as the measurement tolerance.

\begin{tabular}{|c|c|c|c|c|c|c|}
\hline Gust Case ID & $z_{\text {tip, }}(\mathbf{m m})$ & $z_{t i p, g}(\mathrm{~mm})$ & $\Delta z_{t i p}(\mathbf{m m})$ & $\boldsymbol{\theta}_{\text {tip,c }}\left({ }^{\circ}\right)$ & $\boldsymbol{\theta}_{\text {tip }, g}\left(^{\circ}\right)$ & $\Delta \boldsymbol{\theta}_{\text {tip }}\left(^{\circ}\right)$ \\
\hline $\mathrm{GC} 1$ & 4.0 & 5.8 & 1.8 & -0.11 & -0.18 & -0.07 \\
\hline GC2 & 4.0 & 6.2 & 2.2 & -0.11 & -0.23 & -0.12 \\
\hline
\end{tabular}

Table 2 Wing tip bend and twist 


\section{Control algorithm verification experiment}

As an additional element of the EFT project, an experiment was conducted whose primary aim was to verify the performance of the new control algorithm discussed in sections IV and V above, although other aspects of the gust production were also examined. The CTA rake described in section V was used in this experiment. Outputs from this test and their interpretation now follow.

Initially, the level of repeatability of the gusts produced was examined using control algorithm settings where all vane reservoir pressures were set to the same values. As mentioned in section $\mathrm{V}$, the normal mode of operation of the gust rig consists of generating six repeats of each gust at the specified conditions, with these repeats then being averaged. Fig. 18 shows the time variation of the flow angle measured by Probes R2 and R4 for the 1-cosine gust case with $\mathrm{M}=0.5, \mathrm{t}_{\mathrm{g}}=25 \mathrm{~ms}$ and $\mathrm{P}_{\mathrm{pl}}=6 \mathrm{Bar}$ for all vane reservoirs. For each probe, the average flow angle is plotted (blue line) and also the standard deviation of the six samples (black line). The average line reveals the level of noise which is present in the wind tunnel, which, although being larger for Probe R4 than Probe R2, generally has a peakto-peak variation of less than $0.1^{\circ}$. The gust starting vortex is clearly visible on this trace. The standard deviation line is below $0.1^{\circ}$ during the gust event. This shows a high level of repeatability for consecutive gusts, in common with the ARCADE test.

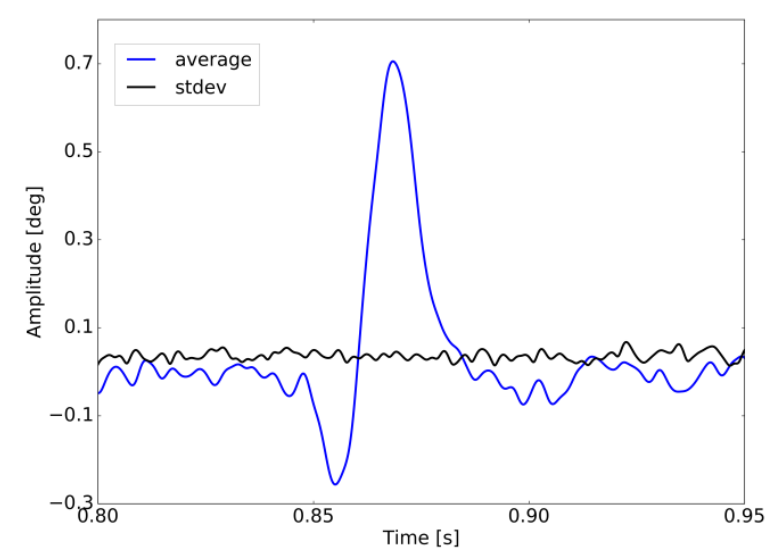

(a) Probe R2

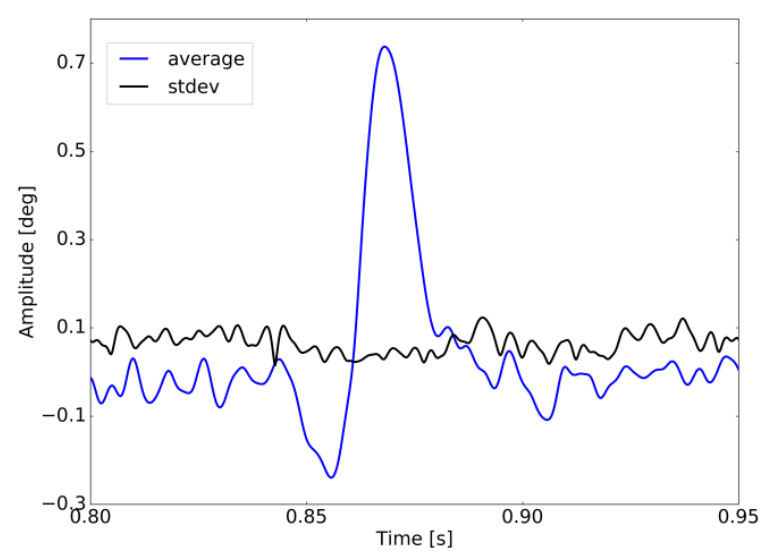

(b) Probe R4

Fig. 18. Repeatability performance - EFT test: $M=0.5, t_{g}=25 \mathrm{~ms}$ and $P_{p l}=6 B a r$

To examine the level of repeatability between separate wind-tunnel experiments, the peak gust amplitude as a function of tunnel height (equivalent to half-model semi-span) was compared between the EFT experiment and the earlier ARCADE experiment, for the same conditions as the case above, see Fig. 19. This figure shows a poor level of repeatability between the two test campaigns. As gust characterisation data from the ARCADE experiment was used to define new control algorithm settings for the EFT experiment, to give constant gust amplitude with tunnel height, concerns were immediately raised as to how successful this had been. Fig. 20 shows the measured variation of gust amplitude using the optimised plenum pressure distribution, to give maximum gust amplitude, for the 1cosine gust case $\mathrm{M}=0.5, \mathrm{t}_{\mathrm{g}}=25 \mathrm{~ms}$, compared with the values predicted from the optimisation procedure. It is clear from this figure that the concerns were justified. Examination of many cases exposed that use of the optimised plenum pressures had not resulted in a clear improvement in the uniformity of the gust amplitude with tunnel height. 


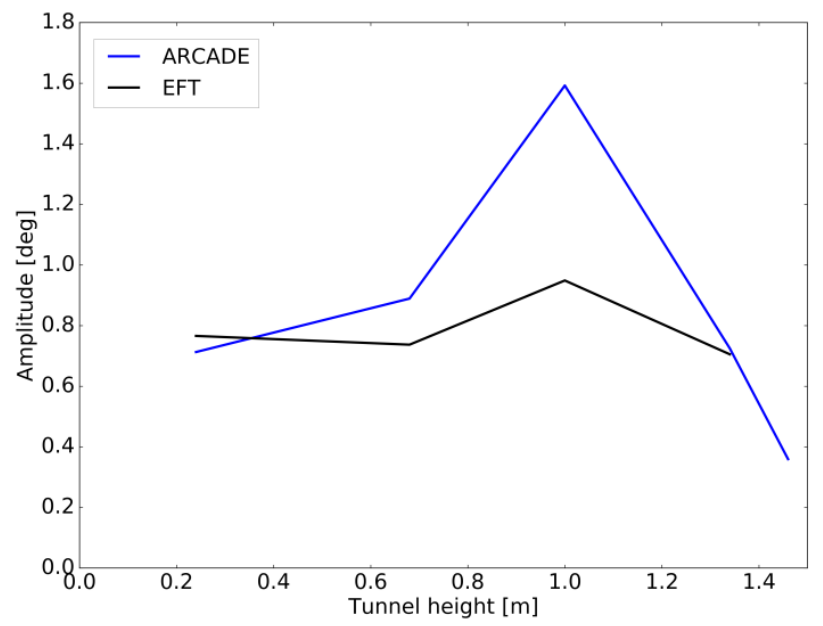

Fig. 19. Comparison of gust amplitude as a function of tunnel height between experiments for gust case $M=0.5, t_{g}=25 \mathrm{~ms}$ and $P_{p l}=6 B a r$

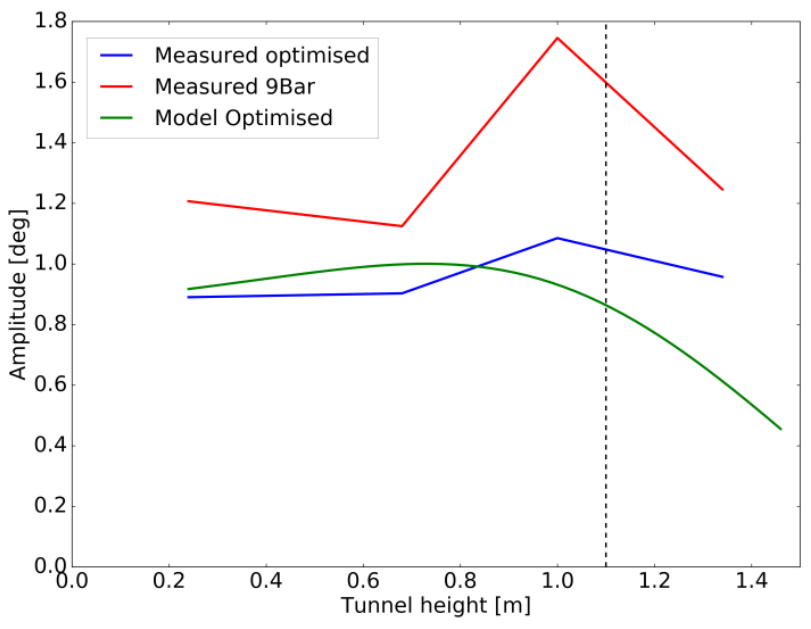

Fig. 20. Comparison of measured and predicted gust amplitude as a function of tunnel height for gust case $M=0.5, t_{\mathrm{g}}=25 \mathrm{~ms}$

The observed lack of repeatability between test campaigns drove a deep investigation to understand the cause of the differences. The investigation covered a thorough analysis of the raw data from all equipment measuring devices and the means by which this was post-processed. Conclusive evidence was obtained from the output of the unsteady pressure transducers positioned in each of the five sections of each gust vane, just upstream of the trailing edge inside the flow exit duct. The raw signals from the transducers (in volts) were converted to a pressure value using a calibration curve and the values from all ten transducers are plotted in Fig. 21 (one transducer is not working), again for the gust case examined above.

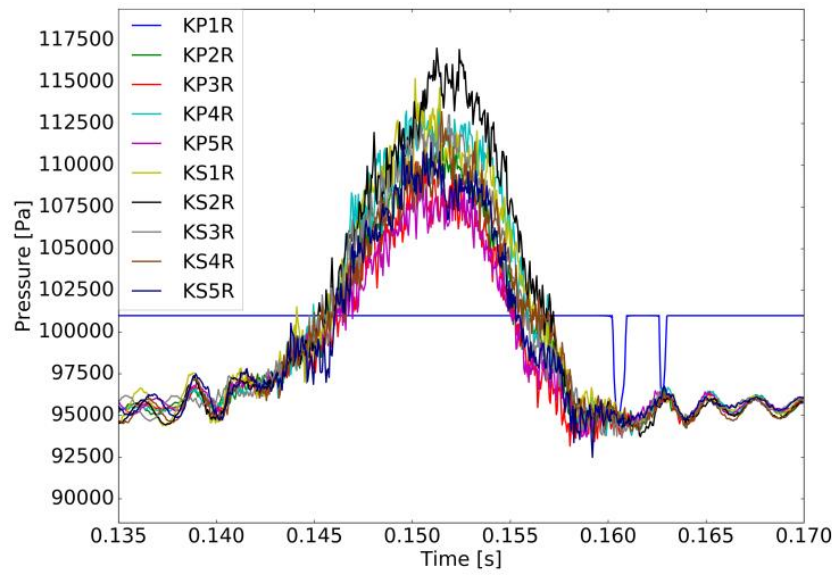

Fig. 21. Calibrated signal from the gust vane pressure transducers for gust case $M=0.5, t_{g}=$ $25 \mathrm{~ms}$ and $\mathrm{P}_{\mathrm{pl}}=6 \mathrm{Bar}$

The most important observation from this figure concerns the change in static pressure during the gust event. Taking the maximum value at the gust peak, the static pressure deviation from the pre-gust value is approximately $200 \mathrm{mBars}$. For a total pressure of $6 \mathrm{Bar}$ in the reservoir and assuming no losses in the air path between the reservoir and the transducer location, a static pressure variation in excess of 3Bar might be expected (at sonic conditions, the variation would be 3.17Bar). The difference between the variation actually obtained and that predicted indicates that significant pressure losses are occurring in the air path.

It is theorised that this may be due to the paddle mechanism for directing the gust to starboard or port, which was added to the internal structure of the gust vane following the 2014 test. This was done as the original (shuttle) mechanism did not function as expected. The effect of adding the paddle mechanism was to create an additional chamber or void inside the gust vane, between the solenoid valves and the trailing-edge ducting. It is possible that this chamber is not fully filling with high pressure air from the solenoid valves during the gust event and/or that significant losses are occurring within it.

A secondary observation from Fig. 21 concerns the variation in the gust peak static pressure values between the nine working transducers, this amounting to approximately $100 \mathrm{mBars}$. This variation may be due to the tolerance in measuring the total pressure in the vane reservoirs, which is believed to be of this order. It is assumed that reducing the pressure losses referred to above will make this level of variation of less consequence. 


\section{Conclusions}

Recent developments of the gust rig facility for the ARA Transonic Wind Tunnel (TWT) have been described. These include electro-mechanical improvements to the basic operation of the rig and also enhancements to the gust vane reservoir pressure control algorithm to produce 1-cosine gusts of constant amplitude (peak flow angle) across a floor-mounted half-model. Experiments both to characterise the gusts produced by the gust rig and to verify the functioning of the new control algorithm, through using a flow-angle measurement rake in the TWT, have been discussed. In addition, an experiment to demonstrate the impact of gusts on a civil aircraft half-model has been presented, in which advanced optical diagnostic equipment has been used. Based on the work undertaken, the following conclusions can be drawn:

- An optimisation procedure has been developed which is capable of taking gust characterisation data as input and producing a distribution of gust reservoir pressure values for the gust vane control algorithm, which will generate an approximately spanwise-constant amplitude 1-cosine gust, with a peak amplitude up to a computed maximum.

- The gust rig can blow quantifiable gusts, in terms of duration and shape, at transonic speeds over a halfmodel, in concert with equipment capable of measuring accurately both the unsteady static pressure field on the wing and the unsteady model deformation (bend and twist).

- The repeatability of consecutive gusts is good, with the standard deviation in flow angle from six events being consistently lower than $0.1^{\circ}$.

- There is an issue with the internal design of the gust vanes which is leading to significant total pressure losses within the vane. It is strongly believed that this is due to the vane mechanism which produces a gust direction to starboard or port. The implications are that the maximum gust strength is below that which would be expected and that the repeatability between separate gust experiments is below standard.

The final conclusion demands a limited re-design of the internal structure of the gust vanes: this is already underway. When the re-design is implemented, a new characterisation of the gusts produced will take place and the optimisation procedure re-run to generate new data for the gust vane control algorithm. The expectation is that gusts with peak amplitude significantly greater than has been observed to date will be possible. This will be a particularly important improvement at high transonic Mach number ( 0.9 and above), where currently gust peak amplitudes are less than $1^{\circ}$.

As with all ground-breaking developments, the ARA gust facility is maturing through cycles of testing to identify deficiencies followed by performance enhancements. It is believed that the facility is not too far distant from an industrialised state, which when reached will deliver to the aircraft industry a unique means of earlyassessment of the response of aircraft designs to gust impact, including with novel gust alleviation devices, and also high-quality data for validation of advanced multi-disciplinary numerical simulation tools.

\section{Acknowledgments}

The support of Innovate UK and the UK Aerospace Technology Institute (ATI) is acknowledged in funding the work described in this paper, through both the ARCADE (Aerodynamic Research testing and CApability Data Enhancement) and the EFT (Enhanced Fidelity Transonic wing) projects. The last author is employed as a Knowledge Transfer Partnership Associate in conjunction with Dr Mark Quinn at the University of Manchester, funded through the Knowledge Transfer Network by Innovate UK. 


\section{References}

[1] Lancelot P. M. G. J., Sodja J., Werter N. P. M., De Breuker R., "Design and testing of a low subsonic wind tunnel gust generator”, In Proceedings of IFASD 2015, St. Petersburg, Russia, July 2015.

[2] Ricci S. et al., "Design and wind tunnel test validation of gust load alleviation systems”, AIAA 2017-1818, January 2017.

[3] Certification Specifications for Large Aeroplanes CS25, European Aviation Safety Agency, 2017.

[4] Allen N. J., Quinn M. K., "Development of a transonic gust rig for simulation of vertical gusts on half-models", AIAA 20152403, June 2015.

[5] Greenwell D., "Flow Angle Calibration for Cross-Wire Probes”, ARA TN AC2017/6, February 2017

[6] Lawson S., Greenwell D., Quinn M., “Characterisation of buffet on a civil aircraft wing”, AIAA 2016-1039, June 2016.

[7] Gregory J., Asai K., Kameda M., Liu T. and Sullivan J., "A review of pressure-sensitive paint for high-speed and unsteady aerodynamics", Proceedings of the Institution of Mechanical Engineers, Vol. 222, Part G: Journal of Aerospace Engineering, 2008, pp. 249-290.

[8] Innovative Scientific Solutions Inc., "Fast-Response Pressure Sensitive”, URL: http://www.psp-tsp.com/index.php?id=108 [cited 27 November 2017]

[9] McCormick N., Lord J., “Digital Image Correlation”, Materials Today, Vol. 13, Issue 12, pp. 52-54.

[10] Kjer H., Wilm J., "Evaluation of surface registration algorithms for PET motion correction", BSc Thesis, Technical University of Denmark, 2010 